Resenhas 


\section{Versões de um mestre}

\section{Alexandre Koji Shiguehara ${ }^{I}$}

$\mathrm{O}$ TíTUlo do ensaio que abre o livro Entre a literatura e a história, de Alfredo Bosi (2015), tem a forma de uma pergunta desconcertantemente simples e direta: "A poesia é ainda necessária?". Longe de ser apenas retórica, a pergunta exprime de fato uma inquietação funda, radicada na postura ética do crítico desde sempre fiel a uma visão da literatura que jamais a rebaixa ao âmbito do tecnicismo ou do academicismo estrito - vale dizer, jamais deixa de considerar o engaste incontornável entre a literatura e a vida.

Bastaria relembrar, a respeito disso, um ensaio fundamental como "Poesia resistência"; ou a menos conhecida atuação de Bosi, desde a juventude, em movimentos sociais como os das Comunidades Eclesiais de Base (CEB). A pergunta que nomeia o ensaio mencionado faz pensar no intelectual de olhar atento às contingências do seu tempo, nunca indiferente às transformações que ameaçam tornar cada vez menos humanas as condições em que vivemos. Após indagar sobre o lugar da poesia no mundo contemporâneo, Bosi reafirma ainda uma vez a sua necessidade absoluta, como instância de resistência à reificação, à violência e à fraude do discurso ideológico.

A tarefa a que se propuseram $\mathrm{Au}-$ gusto Massi, Erwin Torralbo Gimenez, Marcus Vinicius Mazzari e Murilo Marcondes de Moura - organizadores de Reflexão como resistência: homenagem a Alfredo Bosi - tem a complexidade que eles próprios registram no texto de apresentação do volume, ao comentar a dificuldade da escolha do título:
Todo o itinerário de Alfredo Bosi não é o de um homem de letras comum: sua perspectiva crítica guarda raríssima amplitude. Como dar a ver o enlace entre a vivência tão entranhada da poesia e o pendor para o pensamento filosófico? Como abarcar num título os traços marcantes do professor e do militante? Algum aspecto parecia escapar sempre. Como fazer justiça à complexidade do homenageado? $\mathrm{O}$ núcleo vivo da reflexão deve resistir às reduções. (p.13)

$\mathrm{O}$ intuito nada simples da publicação se cumpriu, entretanto, com a reunião de um conjunto extenso e necessariamente heterogêneo de textos, organizados em sete seções que, por assim dizer, assumem estruturalmente no livro uma abertura para o diálogo - característica assinalada por muitos dos 52 autores como qualidade particularmente distintiva do homenageado.

“Abertura", "Cartas na mesa", "Escritos revisitados", "Crítica de ouvido", "Leituras em diálogo", "Depoimentos" e "Ensaios de estima": as seções de $R e^{-}$ flexão como resistência acolhem uma diversidade notável de abordagens e de pontos de vista - ou, para usar termos reconhecidamente caros a Bosi, de tons e de perspectivas. O livro é composto de poemas, uma partitura musical, cartas de agradecimento, depoimentos pessoais, textos de apresentação de livros do crítico, ensaios de sua autoria ou a respeito de sua obra ou simplesmente de sua predileção. A homenagem se abre, assim, a diferentes ângulos de visão e a diversas vozes para contemplar, além da inesti- 
mável contribuição intelectual do homenageado, a sua dimensão humana, que completa aos olhos do leitor uma figura realmente muito singular.

É de fato impossível deixar de assinalar o tom afetivo que rege grande parte dos textos. Não apenas os da seção de "Depoimentos" ou os poemas da "Abertura" - entre os quais o belíssimo "Retrato", de Ecléa Bosi (1936-2017) -, mas também algumas das "Leituras em diálogo", espaço reservado a reflexões sobre aspectos da obra de Alfredo Bosi. Muitos dos autores foram alunos do crítico ou tiveram suas trajetórias sensivelmente influenciadas pelo diálogo direto com ele ou com a sua bibliografia, o que explica as recorrentes expressões de gratidão e reconhecimento.

Já da seção "Cartas na mesa", destaca-se nesse sentido uma carta de Raduan Nassar, datada de 25 de fevereiro de 1999, na qual o escritor agradece a Bosi pelo seu ensaio "Camus na festa do Bom Jesus", sobre a novela "A pedra que cresce", do autor franco-argelino:

Se contei poucas horas depois com o silêncio para acompanhar a tua análise, transitei por outro lado, o tempo todo, entre a leitura do ensaio e o sentimento de que você estivesse me estendendo a mão através dele, $\mathrm{o}$ que se confirmou aos meus olhos efetivamente na exortação cheia de luz com que você fecha o teu trabalho [...] Seja como for, foram horas em que fui tocado no coração de modo fundo, quando chegou a acontecer aquela comunhão, uma recompensa insólita para o meu cansaço de noites mal-dormidas [...] Nem precisaria te dizer então que a festa me fez feliz. Obrigado, Alfredo. (p.42)
Trechos como esse vão compondo ao longo do livro, a meu ver, a imagem do crítico para quem a reflexão sobre a literatura - "instância dialógica e aglutinadora por excelência", nas palavras de José Miguel Wisnik (p.204) - parece pressupor o diálogo e, portanto, perfazer-se apenas no encontro com o outro.

É na seção de "Depoimentos" que esses contornos ficam mais nítidos, sobretudo em "O testemunho de velhos militantes: Singela homenagem a Alfredo Bosi", de Paulo de Salles Oliveira. Para escrever o texto, Oliveira entrevistou antigos companheiros de militância do professor na Pastoral Operária, com quem ele trabalhou nos anos de 1970 no município paulista de Osasco. Os comovedores testemunhos - de ex-operários, líderes comunitários, assistentes sociais - ratificam o perfil ético do humanista cujo pensamento não se separa da ação e mantém com ela profunda coerência.

Ao lado desse texto, figuram depoimentos do músico Ivan Vilella, do romancista e professor da UFRJ Marco Lucchesi e de colegas de Universidade de São Paulo como Fernando Paixão, Jacques Marcovitch, Pedro Garcez Ghirardi e Ulpiano T. Bezerra de Menezes. O desse último, diferentemente dos demais, não tem foco específico na atuação de Alfredo Bosi na Universidade, mas nos rumos preocupantes da Faculdade de Filosofia, Letras e Ciências Humanas da USP, dos tempos da Rua Maria Antônia até os dias de hoje. Uma ampliação temática que contribui para descortinar no livro, em complemento ao perfil pessoal e intelectual de Bosi, algo das circunstâncias concretas de sua produção e de seu cotidiano como docente - ou, numa outra palavra acionada com frequência pelo professor e crítico, algo do seu horizonte. 
A rarissima amplitude da perspectiva crítica de Alfredo Bosi, observada pelos organizadores do livro, é contemplada principalmente nas seções "Escritos revisitados" (composta de dois artigos do próprio Bosi, um sobre Fogo morto, de José Lins do Rego, outro sobre a presença de Camões em Jorge de Lima), "Crítica de ouvido" (textos de apresentação de livros do homenageado), "Leituras em diálogo" e nos "Ensaios de estima".

Como se lê no texto de quarta-capa e no de apresentação do volume, assinado pelos organizadores, é possível notar durante a leitura do livro a fidelidade de Bosi a certos escritores: Antonio Vieira, Machado de Assis, Graciliano Ramos e Jorge de Lima, por exemplo, formam um arco de afinidades eletivas. Ao mesmo tempo, a recorrência de certos termos e conceitos nos textos que refletem sobre a obra do crítico talvez permita reconhecer alguns tópicos fundamentais da sua percepção e absorção pelos contemporâneos. Articulação; mediaçãa; ductilidade da abordagem (sem prejuízo algum do rigor e sem incorrer no ecletismo); consideração da riqueza do problemático ou do contraditório; abertura do olhar para a diversidade, em relação dialética com a atenção minuciosa para o singular; resistência e "consórcio entre vida e literatura" (João Carlos Félix de Lima, p.198) parecem ser algumas dessas noções basilares.

Dois ensaios, o de Cleusa Rios P. Passos e o de Yudith Rosenbaum, abordam aproximações de Alfredo Bosi com a psicanálise. Ambos enfatizam nesse movimento do crítico o seu espírito independente, que enriquece a perspectiva de análise na confluência com determinados conceitos da teoria psicanalítica e, ao mesmo tempo, procura preservar a observação da singularidade de cada sujeito e situação.

Caminham em direção semelhante os comentários de Hélio de Seixas Guimarães em torno de "Uma genealogia dos escritos de Alfredo Bosi sobre a obra de Machado de Assis". O pendor para a mediação e para a relativização é apontado como a tendência marcante, sendo significativa quanto a isso a sugestão de que o Conselheiro Aires, a personagem diplomática por excelência, possa ser lido como alter-ego do próprio Bosi.

Antes de comentar os ensaios de Brás Cubas em três versões (Bosi, 2006), Marcus Vinicius Mazzari relembra considerações teóricas de Alfredo Bosi no último ensaio de Céu, inferno (Bosi, 2003), sublinhando a observação de que os muitos perfis de um fenômeno literário não devem ser jamais substituídos por dados exteriores ao próprio fenômeno. Coerente com esse pressuposto hermenêutico fundamental, indica o texto de Mazzari, é a leitura integradora do romance machadiano realizada por Bosi, que procura "surpreender na trama romanesca a interação viva dos vetores formais, existenciais e miméticos, sem atribuir a nenhum deles o papel de instância última, isto é, monocausal e sobredeterminante" (p.224).

É principalmente de articulação, portanto, o trabalho do crítico que reconhece a irredutibilidade da literatura a elementos externos a ela mesma, mas também não descuida de suas relações com a sociedade e a história. Nas suas considerações sobre os ensinamentos de Bosi, José Miguel Wisnik ressalta a naturalidade do seu trânsito por campos muito variados - a filosofia, a antropologia, a sociologia, a psicologia, a história -, mas em especial o rigor cuidadoso e 
exigente com que o crítico articula os diversos dados na análise das obras.

Nesse percurso as tensões são inescapáveis, e mais de um autor identifica na perspectiva crítica de Bosi a percepção do problemático não como um entrave paralisante, mas como ponto de partida fecundo. "Essa tensão manifesta-se nas dualidades em que o crítico divisa o fato e o problema, ou o fato como problema, para guardar a sábia precaução de Otto Maria Carpeaux" (p.97), escreve Alcides Villaça. André Luís Rodrigues, estudando os trabalhos de Alfredo Bosi sobre Antonio Vieira, detém-se em dado momento na expressão "riqueza das suas contradições", qualidade notada pelo crítico na obra do grande orador jesuíta (p.104). Encontra nela o indício de que Bosi atribua parte do valor dessa obra justamente aos problemas que ela apresenta: "rica porque contraditória", sugere Rodrigues.

Problemática também, já que infinitamente complexa, é a singularidade do sujeito, enigma diante do qual o crítico homenageado não se retrai. E persistir na investigação da matéria densa da subjetividade não deixa de ser um modo de resistência. Parece sugeri-lo a seguinte formulação de Alcides Villaça:

Numa época marcada pelas exterioridades fáceis e fórmulas de prestígio midiático $[\ldots]$, a condição mesma da subjetividade sofre atropelos. Quando o pensamento surge ancorado na consistência de seu sujeito, daquele eu profundo que se reconhece a si mesmo e quer reconhecer o outro no mesmo movimento, o compromisso crítico vive de perfazer o caminho difícil entre as instâncias da singularidade e da universalidade. (p.96)
Entre tantos textos de grande interesse, dos quais só foi possível mencionar aqui uma pequena parte, cabe um destaque ao de João Carlos Félix de Lima, que se dedica à formação intelectual do homenageado - e constata, vale insistir ainda uma vez, a firme vinculação dos caminhos do seu pensamento ao seu itinerário pessoal.

Parafraseando a questão proposta por Bosi no ensaio que citei na abertura deste texto, é fácil dizer que o diálogo com a sua obra viva e inspiradora segue e seguirá sendo absolutamente necessário - e que a profunda dignidade da figura retratada em Reflexão como resistência é um alento valioso, ponto de luz intensa na escuridão dos dias que vivemos.

\section{Referências}

BOSI, A. Céu, inferno: ensaios de crítica literária e ideológica. São Paulo: Duas Cidades; Editora 34, 2003.

. Brás Cubas em três versões: estudos machadianos. São Paulo: Cia. das Letras, 2006.

BOSI, A. Entre a literatura e a história. 2 ed. São Paulo: Editora 34, 2015.

MASSI, A. et al. (Org.) Reflexão como resistência - Homenagem a Alfredo Bosi. São Paulo: Cia. das Letras; Edições Sesc, 2018.

Alexandre Koji Shiguehara é doutor pela Faculdade de Filosofia, Letras e Ciências Humanas da Universidasde de São Paulo. É funcionário da Fundação Nacional de Artes. @-alexandre.shk@gmail.com / https://orcid.org/0000-0002-2684-7387

Recebido em $1^{\circ} .2 .2020$ e aceito em 14.2.2020.

I Fundação Nacional das Artes, São Paulo, São Paulo, Brasil. 